\title{
Study on the Subjectivity of Nursing Students Regarding Emotional Laborers
}

\author{
Sunyoung Jang ${ }^{1}$ \\ ${ }^{1}$ Associate Professor, Department of Nursing, Hanseo University, South Korea, sjang@hanseo.ac.kr
}

\begin{abstract}
The purpose of this study was to identify the subjectivity on emotional laborers perceived by nursing students, describe the characteristics of each type, and to understand the typology of emotional laborers, and the study applied Q-methodology. A total of 154 th year students who were enrolled in the Department of Nursing at University A were asked to classify 36 statements about emotional laborers. The collected data were analyzed using the QUANL PC Program. Based on the result of this study, nursing students' perception of emotional laborers was classified into three factors. The types of subjectivity on emotional laborers are the following; 'emotional laborers protection plan centered type', 'emotional laborers phenomenon identification type', and 'emotional worker side effects cause identification type'. As a result of analyzing subjectivity on emotional laborers using the PC QUANL program, it emerged as three factors, accounting for $58.81 \%$ of the total variance. Factor 1 was $38.27 \%$, factor 2 was 13.34\%, and factor 3 was $7.20 \%$. Among the 15 survey subjects, 6 were identified as factor 1,6 were factor 2 , and 3 were factor 3 . Research on this subjectivity will help to transform the perception of emotional laborers in our society. In addition, by presenting the subjective structure and characteristics of each type of nursing students' perception of emotional laborers as prospective medical personnel, it is intended to provide basic data for the development of differentiated educational programs.
\end{abstract}

Keywords: Emotional Laborers, Nursing Student, Subjectivity, Q-methodology

\section{Introduction}

Emotional labor was first defined in the book "The Managed Heart" by Arlie Russell Hochschild, an emeritus professor at the University of Berkeley, USA, which refers to labor that involves suppressing and controlling one's own emotions in order to fit into the emotions of others like how an actor acts[1]. It is a form of work that emerged as the industry was advanced and the number of service laborers increased. In certain occupations, an employee is expected to tolerate a certain degree of emotional and psychological stress, and the employer (company) expects an increase in sales and profits from it, and such a service is called emotional labor. Emotional labor presupposes an employer, employee, and customer (consumer) relationship, and in almost all cases the degree of emotional control expected is an issue. Therefore, the positive emotions of employees have a positive effect on customers[1]. Emotional labor can be viewed essentially as a commodification of emotional work as it manages emotions and contributes to the employer's increase in profits, and in this commodification process, service workers are estranged from their own feelings at the workplace[1].

In recent years, as hospitals have increased rapidly in quantity, intensifying competition among hospitals and increasing demands for services of medical consumers, each medical institution is in a rush to change its direction to patient-centered and medical consumer-centered medical management. In

Received: May 02, 2021; $1^{\text {st }}$ Review Result: June 16, 2021; $2^{\text {nd }}$ Review Result: August 10, 2021 Accepted: September 30, 2021 
addition, medical institutions are reinforcing kindness education at customer contact points for medical staff in order to provide medical services to meet the needs of medical consumers, and they are constantly monitoring whether appropriate rules of expression and behavior are observed in the interaction between medical staff and patients[2]. Due to this reality, medical personnel have to meet the norms of expressing emotions demanded by the organization, perform their work smoothly, and perform emotional labor in which they have to manage their emotions in order to obtain promotions or achievements[3]. In particular, nurses spend most of their time on patients in hospitals and at the same time play a role of coordination between doctors, peer nurses, and other departments, so the effort of nurses' emotional management can be regarded as an area of nursing work[4].

However, in hospitals, it is taken for granted that nurses provide friendly services for customer satisfaction, and the importance of emotional management, which occupies a large portion of the job performance process, is not recognized. A more serious problem is that although nurses are labor subjects who directly perform emotional labor, they are not even aware of these labors as emotional labor[3]. While performing these intense mental service tasks, nurses experience mental fatigue and job stress, and prior studies on coping strategies have been conducted in relation to these phenomena. As a result, it was revealed that the emotional labor of nurses has an effect on job stress and turnover[3][4].

However, there are no studies of emotional laborers pertaining to nursing students. In this study, the Q-methodology is used to allow the understanding of the characteristics of each type according to the structure of human subjectivity, and begins from the perspective of the actor rather than the assumption of the researcher. Since nursing students' perception of emotional laborers is a subjective and unique experience, it is an appropriate research method to confirm the types of nursing students' perceptions of emotional laborers through the Q-methodology, which is a research method that considers the subject's subjectivity.

Therefore, this study aims to understands the subjectivity structure of emotional laborers from the perspective of nursing students as a preliminary nurse before going to the nursing field, and intend to provide basic data for developing differentiated educational programs according to the characteristics of each type of emotional laborers perception and seek ways to manage emotional labor of nurses.

The purpose of this study was to investigate the types and characteristics of subjective perceptions of emotional laborers of nursing students by applying Q-methodology, and to provide basic data for providing information on nursing students dealing with emotional laborer patients and suggesting strategies for nursing student education. The specific research objectives for this are as follows.

1) Typify nursing students' subjective perception of emotional laborers.

2) Analyze and describe the characteristics of nursing students' perceptions of emotional laborers by type.

\section{Research Methods}

\subsection{Research Design}

To achieve the purpose of the study, after reviewing literature, media data and previous studies on emotional laborers, the Q methodology will be used discover the subjectivity of seeing the types of subjective perceptions of emotional laborers in nursing students who have experienced emotional laborers.

\subsection{Selection of Q-Population and Q-Sample}

The Q population was derived through a review of domestic and foreign literature, open questionnaires, and individual in-depth interviews to extract comprehensive statements about the effects 
on emotional laborers, centering on current nursing students. Through this process, more than $200 \mathrm{Q}$ populations are derived, and in addition, a total of $100 \mathrm{Q}$ populations are extracted by integrating documents collected through review of domestic and foreign related documents. The final 36 samples with high discrimination power were selected after reviewing and revising the extracted Q samples of this study.

\subsection{Selection Method of P-Sample}

Q-methodology is a qualitative research study that emphasizes individual inertia by focusing on differences in meaning or importance within individuals, not differences between individuals, and it is based on the small sample doctrine that when the P sample grows, several people are biased to one factor, and its characteristics are not clearly revealed[5]. In the sample P of this study, a total of 15 students who were enrolled in a nursing department, who were informed of the purpose of the study and gave voluntary consent, were selected.

\subsection{Q-Classification and Data Analysis Method}

The Q-classification process is a process in which each individual makes a voluntary definition of emotional laborers by classifying the subjects selected as $\mathrm{P}$ sample using a forced normal distribution method with a statement of Q sample[6]. Data were collected using Q cards for 14 students in the Department of Nursing at OO University. The time required for one subject to complete the Qclassification was generally 30-45 minutes. The distribution map of the Q sample was classified from strong positive to strong negative according to the importance of their opinions for the statements selected by the study subjects as Q samples. Statements on emotional laborers (Q1) were classified on a 12-point scale. After that, a follow-up interview was conducted with the subjects regarding the statements classified at both ends. For the Q factor analysis, principal component factor analysis (varimax) method was used. The classification of the type was selected based on the Eigen value 1.0 or higher in consideration of the result calculated by inputting the number of factors in various ways and the total explanatory variance. The collected data were scored with the number of conversion points assigned to each of 1 to 12 points, centering on the cards that were forcibly distributed in the Q sample distribution table. The assigned conversion scores were coded in the order of Q sample number and processed by principal factor analysis by the QUANL PC Program. The data were analyzed using the QUANL PC program[7-9].

\subsection{Ethical Consideration of Research Subjects}

After obtaining the subject's voluntary consent before the study, it was explained that it is possible to discontinue joining the study at any time. In order to respect the rights of the subject and to ensure the privacy and confidentiality of their identity and personal information, all data collected through this study was processed anonymously during the entire data analysis process, coded, and Q-sorted.

\section{Results}

In order to analyze the subjectivity on emotional laborers of nursing students by type, first, the characteristics of each type were described, focusing on the statements belonging to each type. The $\mathrm{Q}$ response of the P sample (research participant) was divided into upper and lower questions, and three factors were extracted. In Q-methodology, the higher the factor weight among the people belonging to each type, the more typical or ideal people representing that type. 
In order to analyze the characteristics of each type of emotional laborers, it was interpreted by giving meaning, focusing on the statements with a standard score (z-score) of \pm 1.00 or more among the classified statements. In this study, there were 6 people in type 1, 6 people in type 2, and 3 people in type 3 who had factor weights of 1.0 or higher.

As a result of analyzing subjectivity on emotional laborers using the PC QUANL program, it emerged as three factors, accounting for $58.81 \%$ of the total variance. Factor 1 was $38.27 \%$, factor 2 was $13.34 \%$, and factor 3 was $7.20 \%$. Since factor 1 has $38.27 \%$ explanatory power, it can be seen as the factor that most largely explains subjectivity on emotional laborers [Table 1]. Among the 15 survey subjects, 6 were identified as factor 1, 6 were factor 2, and 3 were factor 3 . People for each factor refer to groups with similar responses to emotional laborers.

[Table 1] Eigen Value, Variance, and Cumulative Percentage

\begin{tabular}{|c|c|c|c|}
\hline & Type I & Type II & Type III \\
\hline Eigen Value & 5.7402 & 2.0010 & 1.0796 \\
\hline Variance(\%) & .3827 & .1334 & .0720 \\
\hline Cumulative( \% ) & .3827 & .5161 & .5881 \\
\hline
\end{tabular}

The types of subjectivity on emotional laborers calculated by this type analysis method are as follows.

- Emotional laborers protection plan centered type: The subjects belonging to type 1 consisted of a total of 6 subjects. Statements in which the subject of type 1 showed strong agreement were, 'Customers and consumers should be caring and respectful for emotional laborers. $(Z=1.75)$ ', 'Excessive emotional labor can lead to post-traumatic stress disorder. $(Z=1.65)$ ', 'In order to reduce emotional labor, it is necessary to constantly assess the level of stress of workers and form alternatives. $(Z=1.65)$ ' [Table 2]. In type 1, the subject with the highest factor weight was 9 (4.4473), and the most agreed statements were 32 and 22. Statements in which type 1 subjects showed strong disagreement were, 'Emotional labor may be eligible for workers' compensation. $(Z=-1.88)$ ', 'Emotional laborers emerge from companies that force kindness only to sell products. $(Z=-1.76)$ ', 'In the case of care workers, emotional labor is difficult to be recognized due to the prejudice of marginal work. ( $Z=-1.72)$ ' [Table 2]. In type 1, the subject with the lowest factor weight was 12 (0.3404), and the most negative statements were 23 and 12 .

The characteristic of type 1 is that consumers should try to be caring about and understanding emotional laborers with regard to emotional laborers. In the coming society, the number of emotional laborers will increase, so it will be necessary to prepare policies for business, government and social protection. In addition, it was said that workers engaged in emotional labor should find ways to reduce and overcome their own stress. Therefore, type 1 was named 'emotional laborers protection plan centered type'.

- Emotional laborers phenomenon identification type: The subjects belonging to type 2 consisted of a total of 6 subjects. Statements in which the subject of type 2 showed strong agreement were, 'Face-toface jobs facing customers directly undergo emotional labor. $(Z=1.95)$ ', 'Occupations that provide services undergo emotional labor. $(Z=1.72)$ ', 'Emotional laborers are created by stereotypes that employees naturally exist for customers. $(Z=1.69)^{\prime}$ [Table 2]. In type 2, the subject with the highest factor weight was 1 (3.8300), and the most agreed statements were 4 and 5. Statements in which type 2 subjects showed strong disagreement were, 'Younger people suffer more emotional labor. $(Z=-2.23)$ ', 'Emotional labor may be eligible for workers' compensation. $(\mathrm{Z}=-1.57)$ ', 'Customers consider consumers to be in the higher position and take it for granted that they should receive satisfactory service. ( $Z=-1.50)$ ' [Table 2]. In type 2 , the subject with the lowest factor weight was 13 (0.6841), and the most negative statements were 36 and 23 .

As for the type 2 trait, they think it is necessary to understand the phenomenon of progressively 
increasing emotional laborers. In modern society, emotional labor continues to increase due to changes in the job structure. In this situation, it would be the most important to grasp the phenomena related to emotional labor, and this would be an important clue for preparing for the future society. The phenomenon that appears with the increase in emotional labor is considered a natural and natural change according to social change. Therefore, type 2 was named 'emotional laborers phenomenon identification type'.

- Emotional worker side effects cause identification type: The subjects belonging to type 3 consisted of a total of 3 subjects. Statements in which the subject of type 3 showed strong agreement were, 'Customers consider consumers to be in the higher position and take it for granted that they should receive satisfactory service. ( $Z=2.18)$ ', 'Consumers' selfish behavior increases emotional labor. $(Z=1.75)$ ', 'Sexual harassment and abusive language can cause emotional labor. $(Z=1.63)$ ' [Table 2]. In type 3, the subject with the highest factor weight was 6 (1.2164), and the most agreed statements were 30 and 15 . Statements in which type 3 subjects showed strong disagreement were, 'Emotional labor may be eligible for workers' compensation. $(Z=-2.12)$ ', 'Emotional laborers will have a lot of domestic discord. ( $Z=-2.11)$ ', 'Younger people suffer more emotional labor. ( $Z=-1.48)$ ' [Table 2]. In type 3, the subject with the lowest factor weight was 10 (0.7837), and the most negative statements were 23 and 8 . Type 3 tries to think about and address the causes of emotional laborers. Most emotional labor is thought to be caused by selfish or inappropriate demands from consumers. It was thought that if a plan to reduce these causes was devised, it would be possible to reduce the stress caused by emotional labor and the damage to workers. Since most of the experiences experienced by emotional laborers are caused by consumers, they did not think that it would be influenced by the characteristics of the emotional laborers or that the results would affect their surroundings. Therefore, type 3 was named 'emotional worker side effects cause identification type'.

[Table 2] Representative Items and Z-score of Emotional Laborers

\begin{tabular}{|c|c|c|c|c|c|}
\hline \multicolumn{6}{|c|}{ Representative items of type } \\
\hline Factor & Type & No & Representative items & Mean(SD) & Z-score \\
\hline \multirow{10}{*}{$\begin{array}{l}\text { Type1 } \\
(\mathrm{N}=6)\end{array}$} & \multirow{5}{*}{ Factor 1} & 32 & $\begin{array}{l}\text { Customers and consumers should be caring and respectful } \\
\text { for emotional laborers. }\end{array}$ & $9.33(0.816)$ & 1.75 \\
\hline & & 22 & $\begin{array}{l}\text { Excessive emotional labor can lead to post-traumatic stress } \\
\text { disorder. }\end{array}$ & $9.17(1,329)$ & 1.65 \\
\hline & & 25 & $\begin{array}{l}\text { In order to reduce emotional labor, it is necessary to } \\
\text { constantly assess the level of stress of workers and form } \\
\text { alternatives. }\end{array}$ & $9.00(1.549)$ & 1.65 \\
\hline & & 34 & $\begin{array}{l}\text { Government should protect emotional laborers through } \\
\text { education, public service advertisements, campaigns, etc. }\end{array}$ & $8.83(2.041)$ & 1.65 \\
\hline & & 33 & $\begin{array}{l}\text { Employers should protect their workers by developing an } \\
\text { emotional labor manual. }\end{array}$ & $8.33(1.751)$ & 1.31 \\
\hline & \multirow{5}{*}{ Factor2 } & 23 & Emotional labor may be eligible for workers' compensation. & $3.00(2.530)$ & -1.88 \\
\hline & & 12 & $\begin{array}{l}\text { Emotional laborers emerge from companies that force } \\
\text { kindness only to sell products. }\end{array}$ & $2.33(1.211)$ & -1.76 \\
\hline & & 28 & $\begin{array}{l}\text { In the case of care workers, emotional labor is difficult to be } \\
\text { recognized due to the prejudice of marginal work. }\end{array}$ & $2.83(2.137)$ & -1.72 \\
\hline & & 36 & Younger people suffer more emotional labor. & $2.50(1.225)$ & -1.63 \\
\hline & & 29 & $\begin{array}{l}\text { Emotional labor of nurses increased due to the integrated } \\
\text { nursing care service. }\end{array}$ & $4.50(2.510)$ & -1.13 \\
\hline \multirow{3}{*}{$\begin{array}{l}\text { Type2 } \\
(\mathrm{N}=6)\end{array}$} & \multirow{3}{*}{ Factor3 } & 4 & $\begin{array}{l}\text { Face-to-face jobs facing customers directly undergo } \\
\text { emotional labor. }\end{array}$ & $9.67(1.366)$ & 1.95 \\
\hline & & 5 & Occupations that provide services undergo emotional labor. & $9.00(1.265)$ & 1.72 \\
\hline & & 16 & $\begin{array}{l}\text { Emotional laborers are created by stereotypes that } \\
\text { employees naturally exist for customers. }\end{array}$ & $8.50(1.871)$ & 1.69 \\
\hline
\end{tabular}




\begin{tabular}{|c|c|c|c|c|c|}
\hline & & 10 & $\begin{array}{l}\text { Repetitive emotional labor in the workplace eventually } \\
\text { leads to quitting. }\end{array}$ & 8.67(0.816) & 1.24 \\
\hline & & 7 & $\begin{array}{l}\text { Expert psychological counseling has a positive impact on } \\
\text { emotional laborers' mental health. }\end{array}$ & $8.17(0.753)$ & 1.08 \\
\hline & & 36 & Younger people suffer more emotional labor. & $2.00(0.632)$ & -2.23 \\
\hline & & 23 & Emotional labor may be eligible for workers' compensation. & $3.50(1.871)$ & -1.57 \\
\hline & Factor4 & 30 & $\begin{array}{l}\text { Customers consider consumers to be in the higher position } \\
\text { and take it for granted that they should receive satisfactory } \\
\text { service. }\end{array}$ & $2.50(1.761)$ & -1.50 \\
\hline & & 27 & $\begin{array}{l}\text { Providing rest time helps emotional laborers recover their } \\
\text { emotions. }\end{array}$ & $3.83(1.722)$ & -1.47 \\
\hline & & 29 & $\begin{array}{l}\text { Emotional labor of nurses increased due to the integrated } \\
\text { nursing care service. }\end{array}$ & $4.83(3.251)$ & -1.10 \\
\hline \multirow{10}{*}{$\begin{array}{l}\text { Type3 } \\
(\mathrm{N}=3)\end{array}$} & \multirow{5}{*}{ Factor5 } & 30 & $\begin{array}{l}\text { Customers consider consumers to be in the higher position } \\
\text { and take it for granted that they should receive satisfactory } \\
\text { service. }\end{array}$ & $10.00(0.000)$ & 2.18 \\
\hline & & 15 & Consumers' selfish behavior increases emotional labor. & $9.00(2.000)$ & 1.75 \\
\hline & & 18 & $\begin{array}{l}\text { Sexual harassment and abusive language can cause } \\
\text { emotional labor. }\end{array}$ & $9.00(0.000)$ & 1.63 \\
\hline & & 16 & $\begin{array}{l}\text { Emotional laborers are created by stereotypes that } \\
\text { employees naturally exist for customers. }\end{array}$ & $8.67(3.215)$ & 1.48 \\
\hline & & 25 & $\begin{array}{l}\text { In order to reduce emotional labor, it is necessary to } \\
\text { constantly assess the level of stress of workers and form } \\
\text { alternatives. }\end{array}$ & $8.00(0.000)$ & 1.09 \\
\hline & \multirow{5}{*}{ Factor6 } & 23 & Emotional labor may be eligible for workers' compensation. & $2.00(1.000)$ & -2.12 \\
\hline & & 8 & Emotional laborers will have a lot of domestic discord. & $2.33(1.528)$ & -2.11 \\
\hline & & 36 & Younger people suffer more emotional labor. & $3.33(3.215)$ & -1.48 \\
\hline & & 2 & Emotional labor negatively affects physical health. & $3.67(1.528)$ & -1.38 \\
\hline & & 7 & $\begin{array}{l}\text { Expert psychological counseling has a positive impact on } \\
\text { emotional laborers' mental health. }\end{array}$ & $3.67(0.577)$ & -1.26 \\
\hline
\end{tabular}

\section{Discussions}

As a result of this study, the types of subjectivity on emotional laborers recognized by nursing students were identified as type 1 'emotional laborers protection plan centered type', type 2 'emotional laborers phenomenon identification type', and type 3 'emotional worker side effects cause identification type', and the characteristics of each type will be discussed.

Type 1 in this study was 'emotional laborers protection plan centered type'. They believe that it is important to come up with measures to protect them both nationally and socially, as emotional laborers arise from various occupational groups. Not only workers but also employers are responsible for this, and they believe that nurses are those who do high-level emotional labor, and hospitals should also consider this. As prospective nurses, they anticipate their future and show a positive attitude toward the necessity of preparing concrete plans.

Emotional labor (emotion work) is an individual's effort to externally control facial expressions or gestures to express the emotions required by the organization, and employees of service companies such as airlines and insurance companies, as well as those who are engaged in professional occupations such as lawyers, doctors, and nurses, are also performing emotional labor, distinct from manual labor and mental labor[1]. The behavior of expressing emotions by employees in the service industry directly affects the company's profit creation due to the nature of the business processes they perform. Therefore, employees are required to strategically manipulate their emotions to satisfy a specific psychological state desired by service recipients to create a form of interaction with customers suitable for job performance[10]. 
In recent years, in the medical field, as competition among hospitals increases and demands of medical consumers increase, strategies for hospital staff to control their emotions when responding to patients and maintain a specific emotional state are increasing. Because nurses provide nursing care to patients on the premise of contact and practice centered on human relations and at the same time play a role of coordination among various occupations, the effort of nurses' emotional management can be regarded as an area of nursing work[11]. Therefore, in hospitals, nurses are required to give a sense of trust to patients and their caregivers and to act in a stable manner when performing tasks, and are receiving formal education and supervision so that they can manage and act appropriately for patient satisfaction[12].

According to the social exchange theory, taking into account that the exchange between individuals and organizations has a positive effect on the attitudes of employees toward the organization in the social and emotional aspects[12], in order to offset any complaints that may arise from emotional labor, the company should provide organizational support, and it is necessary to manage systematic support so that employees can perceive them through the operation of a rest time or counseling program for service employees who have been exposed to long-term emotional labor. In addition, considering that care labor strengthens the influence of emotional labor on union attitudes, employers in the care industry need more efforts to reduce the negative reactions of service workers caused by emotional labor. In consideration of the characteristics of care labor, it is necessary to manage the reaction behavior caused by emotional labor through efforts to increase the value of work through provision of organizational protection devices and appropriate compensation for these employees from customers.

Type 2 was 'emotional laborers phenomenon identification type'. They say that in the non-face-toface era when tangible products were produced and sold, emotional labor is bound to increase as the number of occupations that provide services and receive compensation for them increases. However, they thought that the status of the emotional laborers in their current situation, such as the type of stress experienced and the consequences of emotional labor, were not clearly understood, and that a clear formulation was needed. They see that identifying the phenomenon is the biggest clue to solving the difficulties of emotional laborers.

The studies on emotional labor triggered by Hochschild (1983) were an opportunity to awaken the importance of emotional management in organizations[1]. Recently, many studies have given new emphasis and light on the effect of subjective and emotional aspects of human behavior on the health of organization members, such as emotional and psychological welling-being, and actual job performance [13][14].

The performance of emotional labor makes interactions with customers more predictable, helping employees to have appropriate self-emotional control and control, and it is said that by performing emotional labor that follows the organization's norms, it is possible to expect improvement of selfefficacy as well as a sense of accomplishment that successfully fulfilled job demands[15], but Hochschild (1983) argued that, in terms of negative effects in the process of emotional labor, when one's own emotions and the expressions required by the organization conflict with each other, the real self is damaged when emotional dissonance is felt, and it is said that this is a serious self-alienation, resulting in a decrease in self-esteem, job dissatisfaction, and intensification of emotional exhaustion[16].

In particular, Hochschild (1983) argued that emotional labor reflects the emotional efforts of job performers, so it is reasonable to regard this as an area of job performance, and emotional labor, as a job performance, includes not only the meaning of emotional expression efforts, but also the aspect of emotional distortion, it is said that it can act as job stress[1], and Ko, Ji, \& Song (2001) argued that emotional labor, especially emotional distortion, acts as an important variable reflecting the uniqueness of service organizations in that they are a part of job performance and at the same time become stressors, and it was stated that it is necessary to study not only aspects of job performance but also stress[17]. As a result, although the emotional labor of a nurse is an area of nursing work, the need to control the 
negative effects of emotional labor is raised because the emotional expression of a nurse includes not only the effort of emotional expression but also the aspect of emotional distortion.

Type 3 was 'emotional worker side effects cause identification type'. They think that if the cause of the side effects experienced by emotional laborers is resolved, the side effects of workers caused by emotional labor can be resolved. They thought that most of the side effects were caused by customers who dealt with emotional laborers, so controlling the customer's behavior or language would solve many of the injuries of workers. They also stated that emotional laborers themselves would not take for granted or accept the injuries caused by emotional labor, but would need an attitude to think about and resolve the wounds caused by emotional labor.

In order to survive in an environment of infinite competition and rapid change, many modern hospitals have become interested in customers (patients) who have been relatively neglected, and in order to enhance hospital competitiveness and secure profits through customer satisfaction strategies that reflect the needs of "customers" or patients, the commercialization of human feeling was promoted[18].

Therefore, hospitals have introduced the concept of hotel-style customer service to formally teach kindness to nurses and other medical staff, and monitor whether appropriate rules of expression and behavior are observed through continuous surveys on customer satisfaction[14]. As Ferguson (1984) pointed out, the phenomenon that human emotion management activities deviated from the private domain and attributed to the organizational purpose as part of the commercialized labor force in the public domain was applied to nurses, and nurses must hide or distort their actual emotions in accordance with the norm of emotion expression required by the hospital or the workplace in which they work for desirable job performance[18].

Nurses provide skilled nursing care to patients on the premise of contact and practice centered on human relations, and at the same time play a coordinating role to focus the efforts of doctors, peer nurses, and other department staff on the patient, and the nurse's emotional management efforts can be considered an area of nursing work. However, hospitals emphasized customer satisfaction, and as a strategy for long-term customer acquisition by reusing hospitals and attracting referral customers, the hospitals are deeply involved in the behavior of nurses expressing emotions, and accordingly, the expression of emotions by nurses included emotional distortions caused by external force, not individual spontaneity. Therefore, the emotional labor of nurses is increasing, and the workload is increasing due to shadow labor other than the job in charge, but the value of the emotional labor of nurses has not yet been properly evaluated[19]. A more serious problem is that, as Kang (2002) pointed out, although nurses are labor subjects who directly perform emotional labor, they do not recognize such labor as emotional labor[16].

Researchers have studied ways to reduce or alleviate emotional service performance because it acts as job stress, and as a result, several variables influencing emotional labor on job attitude and other outcome variables such as burnout and turnover intention were suggested[14][17]. As the variables, personal characteristics such as self-expression ability, self-control ability, self-efficacy and extrovert personality, job autonomy corresponding to the characteristics of the job itself, and social support such as support from colleagues were considered to be the controlling factors [14][17], and among them, it was social support and self-efficacy that received attention. This is because for that reason, social support regulates the effect of emotional dissonance on psychological well-being, and the higher the level of self-efficacy, the less negative effects arising from emotional expression for job performance, and it is a variable that can be directly managed from the perspective of the organization[14][17][20].

The emotional labor of nurses influences burnout and turnover intention through social support. This means that emotional labor itself is not important, but social support has more important explanatory power for burnout and turnover intention. In other words, when it is perceived that a nurse working in a hospital is being supported or considered by colleagues and supervisors in the organization, which is a 
social environment, when a nurse working in a hospital is exhausted or increased intent to turnover in relation to work, it has implications for the organizational management of nursing managers in that it can influence the negative effects caused by emotional labor and at the same time control from the perspective of the organization or manager.

This study analyzed nursing students' subjective perception of emotional laborers by dividing them into three types. Through this study, it was thought that a change in social perception and policy support for emotional laborers will be needed. In addition, if additional education or discussion about emotional labor is accompanied in the process of nurturing medical personnel, it is thought that it will help to derive active efforts to resolve the side effects of emotional labor, which will continue to increase in the future. The characteristics of each type were divided into 'emotional laborers protection plan centered type', that believes that the protection plan for emotional laborers should be prepared nationally and politically, 'emotional laborers phenomenon identification type', that believes that understanding the current situation of emotional laborers is the most important thing at this time, and 'emotional worker side effects cause identification type' that believes that identifying and solving the causes of side effects caused by emotional labor is the ultimate future task.

Research on this subjectivity will help to transform the perception of emotional laborers in our society. In addition, by presenting the subjective structure and characteristics of each type of nursing students' perception of emotional laborers as prospective medical personnel, it is expected to be used as basic data for the development of differentiated educational programs.

However, because the study was conducted at a single university and the subjects were not selected in consideration of the factors affecting the perception of emotional laborers, and since there is a limitation in generalizing the research results, it is necessary to further verify the type by constructing Q samples with various backgrounds through follow-up studies.

\section{Conclusion}

In this study, through subjective data that explores and analyzes nursing students' subjective perceptions of emotional laborers, an attempt was made by applying Q-methodology to prepare basic data necessary for suggesting changes in emotional laborers perception and the direction of nurses' approach. As a result of this study, it was classified into 3 types. The types of emotional laborers recognized by nursing students were 'Emotional laborers protection plan centered type', 'emotional laborers phenomenon identification type', and 'emotional worker side effects cause identification type'.

This study typified the subjectivity on emotional laborers of nursing students and provided basic data to prepare ways to improve attitudes and perceptions toward themselves and others as emotional laborers in the future. Since this study analyzed and identified the types of emotional laborers perceived by nursing students, it is expected that an educational program that considers the characteristics of each type will be developed. In addition, a qualitative study is proposed to identify various factors influencing nurses as emotional laborers and additional studies on type analysis by selecting samples considering various factors.

\section{References}

[1] A. R. Hochschild, The Managed Heart: Commercialization of human feeling, (Third Edition), University of California Press, (2012)

[2] I. S. Kim, The Role of Self-Efficacy and Social Support in the Relationship between Emotional Labor and Burn out, Turn over Intention among Hospital Nurses, Journal of Korean Academy of Nursing Administration, (2009), Vol.15, No.4, pp.515-526. 
[3] I. A. Park, The effect of nurses' personality, emotinal labor on job attitude, Hanyang University, Master's thesis, (2008)

[4] M. R. Song, K. J. Park, Emotional Labor Experienced by Ambulatory Care Nurses, Journal of Korean Academy of Nursing Administration, (2011), Vol.17, No.4, pp.451-461.

[5] M. Wang, S. Jang, Study of Subjectivity on Well-dying in Nursing Students, Asia-pacific Journal of Psychology and Counseling, (2018), Vol.2, No.2, pp.159-164, http://dx.doi.org/10.21742/APJPC.2018.2.2.27

[6] S. M. Whang, S. W. You, J. Y. Kim, R. G. Kim, Q Methodology and Theory : Consumer Types and Cultural Consumption Characteristics of Korean Society: Who Spends for What Reasons?, Journal of Human Subjectivity, (2006), Vol.13, pp.25-39.

[7] H. Lee, S. Jang, M. Wang, A Study on Patients' Perceptions of Patient Safety (Q method), Asia-pacific Journal of Law, Politics and Administration, (2017), Vol.1, No.2, pp.1-6, http://dx.doi.org/10.21742/AJLPA.2017.1.2.01

[8] M. Wang, S. Jang, A Study on the Subjectivity of Nursing Students on Dating Violence, International Journal of Advanced Nursing Education and Research, (2017), Vol.2, No.1, pp.97-102, DOI:10.21742/IJANER.2017.2.1.17

[9] S. Jang, The Subjectivity for Open Adoption of Nursing Students, International Journal of Advanced Nursing Education and Research, (2018), Vol.3, No.1, pp.57-62.

[10] S. J. Yoon, S. P. Kim, E. M. Kim, Emotional Labor : A Qualitative Study of Organizational Norms about Expressed Emotion, Korean Journal of Labor Studies, (2000), Vol.6, No.1, pp.215-254.

[11] I. S. Kim, The role of self-efficacy and social support in the relationship between emotional labor and burn out, turn over intention among hospital nurses, Journal of Korean Academy of Nursing Administration, (2009), Vol.15, No.4, pp.515-526.

[12] M. S. Joung, K. J. Kim, A study on the effect of emotional labor and leader's emotional intelligence on job satisfaction and organizational commitment for nurses, Korean Journal of Hospital Management, (2006), Vol.11, No.4, pp.1-18, UCI : G704-001432.2006.11.4.004

[13] N. M. Ashkanasy, C. E. J. Hartel, C. S. Daus, Diversity and emotion: The new frontiers in organizational research, Journal of Management, (2002), Vol.28, No.3, pp.307-338, https://doi.org/10.1177/014920630202800304

[14] B. G. Park, Moderating effects of organizational support and self-efficacy on the relationship between emotional labor and job attitudes, Journal of Human Resource Management, (2008), Vol.15, No.1, pp.69-85, UCI : G704001783.2008.15.1.006

[15] B. E. Ashforth, R. H. Humphrey, Emotional labour in service roles: the influence of identity, Acad of Management Review, (1993), Vol.18, No.1, pp.88-115, https://doi.org/10.2307/258824

[16] H. A. Kang, A study on change in nurses' job, Economy and Society, (2002), Vol.55, pp.142-168, UCI: I410-ECN0101-2009-305-012554582

[17] D. W. Ko, S. J. Ji, W. G. Song, Research Articles : Moderating Effects of Perceived Organizational Support on the Negative Influences of Emotional Labor of Hotel Employees, Journal of Tourism Sciences, (2001), Vol.25, No.2, pp.295-314.

[18] S. P. Kim, D. R. Lee, The Effects Of Emotional Labor And Job Context On Service Employees' Psychological WellBeing, Journal of Human Resource Management Research, (2008), Vol.15, No.2, pp.79-102, UCI : G704001783.2008.15.2.006

[19] S. I. Hyun, Emotional labor, emotional competence and customer orientation in hospital nurses, Yonsei University, Master's thesis,(2008)

[20] M. J. Kim, A Comparative Study of the Consequences of Emotional Labor between Korea and U. S. A. : Focused on the relationship between the hotel employees' emotional labor and their job stress., Korean Journal of Hospitality and Tourism, (2006), Vol.15, No.1, pp.35-57, UCI : G704-001024.2006.15.1.010 